\title{
Shedding NHTS Light on the Use of "Little Vehicles" in Urban Areas
}

Kevin J. Krizek, Nancy McGuckin ${ }^{\dagger}$

Keywords: disruptive technology, e-scooters, urban new modes

https://doi.org/10.32866/10777

Transport Findings

Bicycles, scooters, Segways, skateboards, and more are placing new demands on urban streets in big cities. These modes, termed "little vehicles" (LVs) here, share common characteristics. This research leverages the 2017 National Household Travel Survey to understand and benchmark key characteristics for current users and trip characteristics of LVs. Our findings show that young men are the predominant users of these modes for a wide range of purposes, including recreational and social activities, shopping and errands, and work travel. In the biggest metro areas in the United States, three-quarters of the trips by LVs are less than $4 \mathrm{~km}(2.5 \mathrm{mi})$, and half are shorter than $2 \mathrm{~km}(1.2 \mathrm{mi})$ (median) - a distance band that is often considered too far to walk, but shorter than most trips currently taken by car.

\section{RESEARCH QUESTION AND HYPOTHESIS}

City leaders are challenged to reconcile new demands being placed on public streets and sidewalks. Little vehicles (LVs) - bicycles, scooters, Segways, skateboards, and more-are increasingly in competition with private cars, buses, and pedestrians for space on public travelways. These LVs involve wheeled transport that is low-speed and used primarily for trips less than a few kilometers. Being too fast to safely use on sidewalks yet not encouraged to mix with cars, LVs are contributing to increased confusion in major cities, prompting safety concerns from pedestrians due to recent reported fatalities of LV users.

The motivating drive for this article is that little is known about the travelers and types of trips that LVs serve. Increasing signs suggest they fill an emerging niche for US urban travel (Schneider 2018), one competing with cars and ridesharing options. While the growth of rideshare has received considerable attention (Conway, Salon, and King 2018) - and even adaptive measures by cities to accommodate curbside access-practical approaches to comfortably accommodate LVs remain in short supply (Fang, Agrawal, and Hooper 2018). Some research suggests that new modes such as e-scooters are adding to, not detracting from, trips in cities already made via bicycle (Portland Bureau of Transportation 2018). As the use of these intermediary modes of travel grows, the question is: Who uses LVs, for what kinds of trips, and in what kinds of circumstances?

\footnotetext{
* University of Colorado Link: http://www.kevinjkrizek.org

† Link: https://www.travelbehavior.us
} 


\section{METHODS AND DATA}

This research is descriptive and exploratory; our aim is to leverage the 2017 National Household Travel Survey (NHTS) - the only probability-based travel survey that covers the entire United States-to begin to understand and refine the demographic market and characteristics of LV use for future research. The NHTS captured 8,034 bicycle trips, 826 Segway/golf cart trips, and 503 trips where respondents reported having used a scooter, skateboard, or similar device. The small sample of responses for the latter category undermined our confidence to statistically discern the use of one device versus another, but uses of each of these modes share similarities in that they: (1) are banned from sidewalks in most cities and are unwelcome in the streets with cars, thereby experiencing trouble finding the right public space to operate; (2) have similar characteristics in speed and distance of their use-which is notably different than of cars and pedestrians; and (3) are presently under heavy policy scrutiny.

\section{FINDINGS}

According to the 2017 NHTS, LVs are mostly used by young men. Men were twice as likely as women to report a trip using an LV (see Figure 1). This finding is consistent with other studies that showing women's rates of bicycle use are less than men's, largely attributed to feeling less comfortable cycling in risky traffic environments (Dill et al. 2014; Krizek, Johnson, and Tilahun 2005; Emond, Tang, and Handy 2009; Singleton and Goddard 2016). Furthermore, adults ages 18-50 were more likely than other adults to report using an LV on the travel day.

Three-quarters of LV trips are shorter than $4 \mathrm{~km}$ (2.5 mi), and half are shorter than $2 \mathrm{~km}$ (1.2 mi) (median)-a distance band that clearly falls between walk and car trips (see Figure 2A-C). Interestingly, one-quarter of car trips are $3 \mathrm{~km}$ $(1.86 \mathrm{mi})$ or less-a distance that is squarely within the range of LV travel, suggesting the potential for mode shifting some of the shortest vehicle trips in large metro areas. On the other hand, three-quarter of walk trips are $1 \mathrm{~km}(0.62$ $\mathrm{mi}$ ) or less, indicating less overlap in trip distance between walks and LVs.

We aimed to look further at this "mid-range" distance of travel to see how the use of LVs might compare to all travel in the same distance band. According to the 2017 NHTS, for these mid-distance trips (between 1 and $6 \mathrm{~km}$ in length), people use LVs at about the same rate they use taxis and rideshare services (see Table 1). For trips of this distance, roughly one-third of LV use is for recreational purposes (32.8\% in Figure 3)-more than the percentage of all trips. On the other hand, people use LVs noticeably less for shopping and errands relative to trips via all modes of travel- $28 \%$ of LV trips compared to about half of trips by all modes are for shopping and errands (in this distance band). The proportion of LV trips for work and work-related purposes, 
however, is higher-28.8\% of all LV trips compared to just $11.9 \%$ of trips by all modes of travel (again, in the distance band of trips between 1 and $6 \mathrm{~km}$ in length in large metropolitan statistical areas).

LV use is prevalent in large urban areas for trips too far to walk but too short to merit using a private car, ridesharing, or transit. We analyzed information for cities with more than 1 million people because the market for e-scooters, bikeshare, and the like is primarily urban. We examined the characteristics of people who use LVs and found statistically significant differences in some of the demographics of LV users; e.g., at the $90 \%$ confidence level, men were more likely than women and young people were more likely than older people to report using an LV on the travel day. However, the small sample of trips reported in large metro areas by users of LVs in the 2017 NHTS means that we can only tease out limited but important descriptive differences in trip characteristics (Krizek, Handy, and Forsyth 2009).

In terms of trip characteristics, we found that the trip length distribution for LVs fell squarely between walk and private vehicle travel-in the range of 1 to $6 \mathrm{~km}$ distance. Looking further at trips in that distance band, we compared LV travel to travel by all means. While LVs were used for a range of purposes, they were more likely than other trips to be used for social and recreation travel.

This research provides helpful benchmark information for planners and policymakers who are dealing with the increasing phenomenon of LV use in urban areas (Krizek, Sharmeen, and Martens 2018). The available data shows that for mid-range distances in large urban areas, LVs are likely to be used about as much as ridesharing services (about the same mode share). Further, LVs are used for a range of trip purposes, with about a third for recreation, followed by shopping and errands, and work and work-related.

This group of modes is under policy scrutiny at the present time: scooters in many places, but also Segways and bike-shares as they gain popularity. Left uncovered is how bicycle use relates to scooters/e-scooters (e.g., trip distances or frequencies and/or substituting for one another) and how their use relates to larger questions of the travel demand in cities. While this research effort precludes analyzing route characteristics of these trips, we conjecture that safe street space for LV use is in low-supply relative to the demand. LV use could be made more appealing to a broader demographic by prioritizing improvements to streets in city areas with a higher percentage of shorter distance trips.

\section{ACKNOWLEDGMENTS}

Publication of this article was funded by the University of Colorado Boulder Libraries Open Access Fund. 

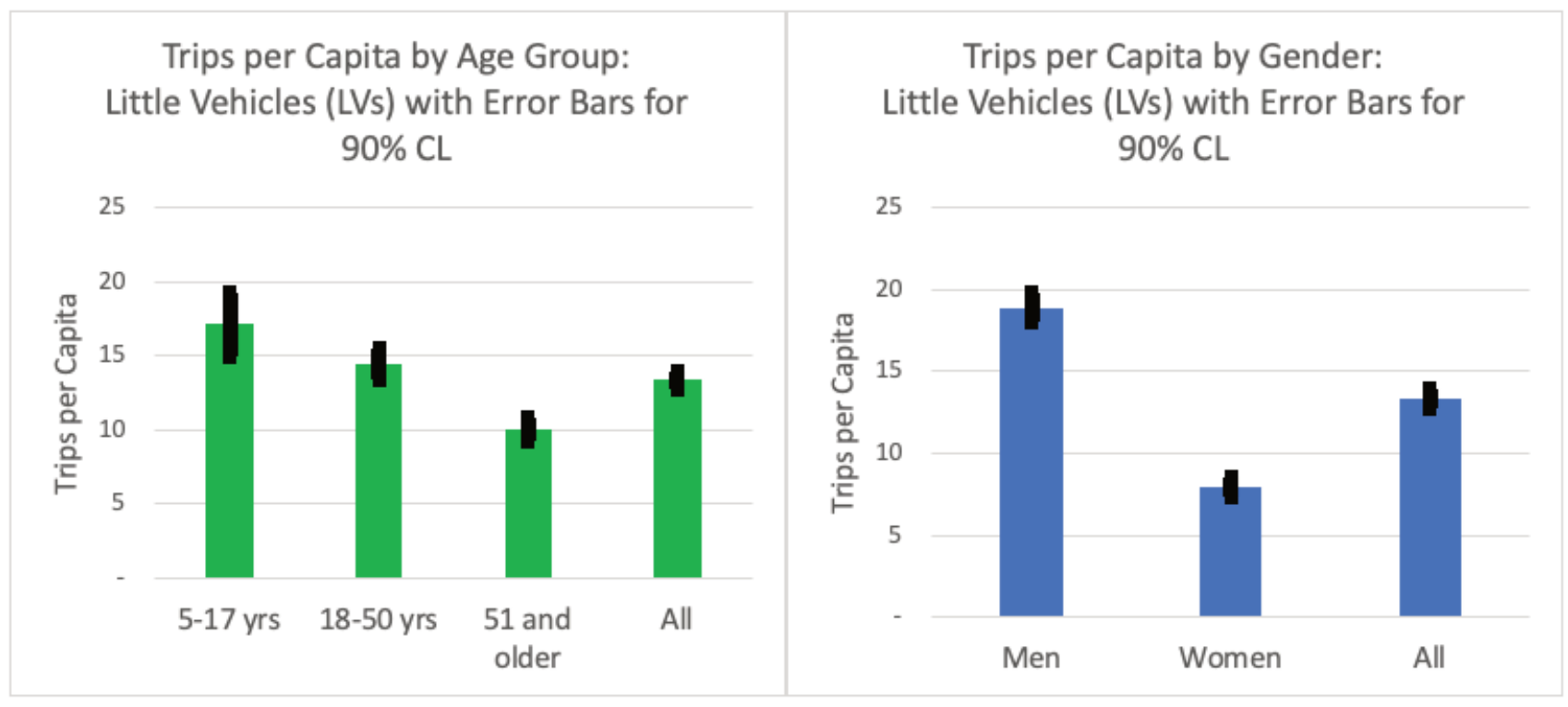

Figure 1: LV Use by Gender and Age (error bars represent 90\% confidence level)

Table 1: Mode Share in Large Metropolitan Statistical Areas for Mid-distance Trips ${ }^{\mathrm{a}}$

$\begin{array}{ll}\text { Private Vehicle Trips } & 76.8 \% \\ \text { Walk } & 12.6 \% \\ \text { Transit } & 5.0 \% \\ \text { Little Vehicles } & 1.8 \% \\ \text { Taxi/RIDESHARE } & 1.5 \% \\ \text { All Other } & 2.3 \%\end{array}$

aTrips between 1 and $6 \mathrm{~km}$ in length 


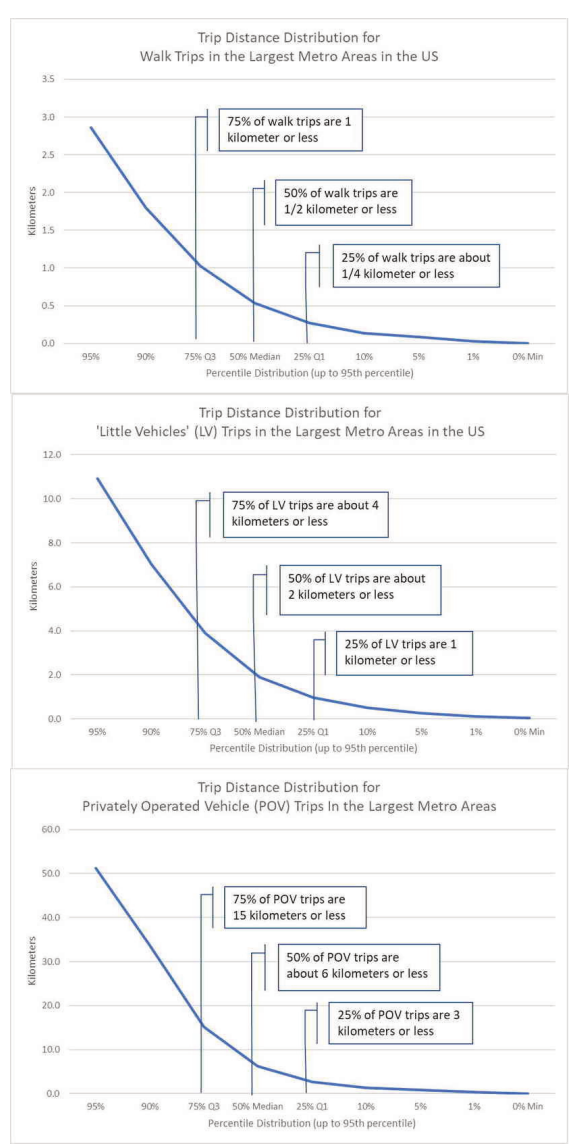

Figure 2: Trip Distance Distribution for Walk, LV, and Private Vehicle Trips in Large US Metro Areas

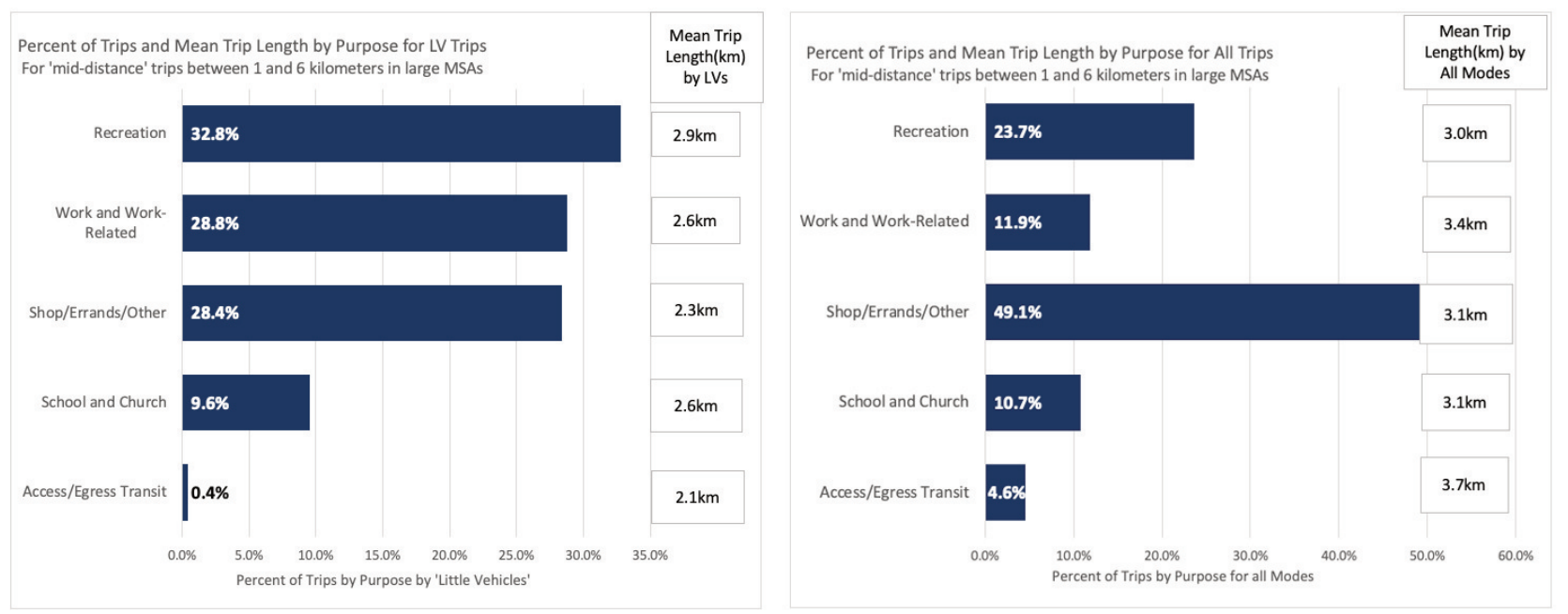

Figure 3: Percent of Trips and Mean Trip Length $(\mathrm{km})$ by Purpose: Comparing LVs and All Modes for Mid-Range Trips in Large US Metro Areas

This is an open-access article distributed under the terms of the Creative Commons Attribution 4.0

International License (CCBY-NC-4.0). View this license's legal deed at https://creativecommons.org/ licenses/by-nc/4.0 and legal code at https://creativecommons.org/licenses/by-nc/4.0/legalcode for more information. 


\section{REFERENCES}

Conway, M., D. Salon, and D. King. 2018. "Trends in Taxi Use and the Advent of Ridehailing, 1995-2017: Evidence from the US National Household Travel Survey.” Urban Science 2 (3): 79. https://doi.org/10.3390/urbansci2030079.

Dill, J., T. Goddard, C. Monsere, and N. McNeil. 2014. "Can Protected Bike Lanes Help Close the Gender Gap in Cycling? Lessons from Five Cities." Urban Studies and Planning Faculty

Publications and Presentations 123. https://pdxscholar.library.pdx.edu/usp_fac/123.

Emond, C. R., W. Tang, and S. L. Handy. 2009. "Explaining Gender Difference in Bicycling Behavior." Transportation Research Record: Journal of the Transportation Research Board 2125 (1): 16-25. https://doi.org/10.3141/2125-03.

Fang, K., A.W. Agrawal, and A. Hooper. 2018. "Electric Kick Scooters on Sidewalks in Virginia but Not in California? A Review of How States Regulate Personal Transportation Devices." Mineta Transportation Institute, Project 1713.

Krizek, K. J., S. L. Handy, and A. Forsyth. 2009. "Explaining Changes in Walking and Bicycling Behavior: Challenges for Transportation Research." Environment and Planning B: Planning and Design 36 (4): 725-40. https://doi.org/10.1068/b34023.

Krizek, K. J., P. J. Johnson, and N. Tilahun. 2005. "Gender Differences in Bicycling Behavior and Facility Preferences.” Research on Women's Issues in Transportation 2: 31-40.

Krizek, K. J., F. Sharmeen, and K. Martens. 2018. "JTLU Special Issue Editorial: Bicycling in Changing Urban Regions." Journal of Transport and Land Use 11 (1). https://doi.org/10.5198/ jtlu.2018.1459.

Le, H. T., R. Buehler, and S. Hankey. 2019. "Have Walking and Bicycling Increased in the US? A 13-Year Longitudinal Analysis of Traffic Counts from 13 Metropolitan Areas." Transportation Research Part D: Transport and Environment 69 (April): 329-45. https://doi.org/10.1016/ j.trd.2019.02.006.

McNeil, N. 2011. "Bikeability and the 20-Min Neighborhood: How Infrastructure and Destinations Influence Bicycle Accessibility." Transportation Research Record: Journal of the Transportation Research Board 2247 (1): 53-63. https://doi.org/10.3141/2247-07.

Portland Bureau of Transportation. 2018. "E-Scooter Findings Report." https://www.portlandoregon.gov/transportation/article/709719.

Schneider, B. 2018. "Why Little Vehicles Will Conquer the City.” https://www.citylab.com/ transportation/2018/06/welcome-to-the-tiny-vehicle-age/563342/.

Singleton, P. A., and T. Goddard. 2016. "Cycling by Choice or Necessity?: Exploring the Gender Gap in Bicycling in Oregon.” Transportation Research Record:Journal of the Transportation Research Board 2598 (1): 110-18. https://doi.org/10.3141/2598-13. 